\title{
Crystallographic and structural transformations of sedimentary chalcedony in flint upon heat treatment
}

\author{
Patrick Schmidt ${ }^{\mathrm{a}, *}$, Sylvie Masse ${ }^{\mathrm{b}}$, Guillaume Laurent ${ }^{\mathrm{b}}$, Aneta Slodczyk ${ }^{\mathrm{c}}$, Eric Le Bourhis ${ }^{\mathrm{d}}$, \\ Christian Perrenoud ${ }^{\mathrm{e}}$, Jacques Livage ${ }^{\mathrm{b}}$, François Fröhlich ${ }^{\mathrm{a}}$ \\ ${ }^{a}$ Muséum national d'histoire naturelle, Departmento de Préhistoire UMR 7194, Centre de spectroscopie infrarouge, CP 57, 57, rue Cuvier 75231 Paris Cedex 05, France \\ ${ }^{\mathrm{b}}$ Chimie de la Matière Condensée de Paris, UPMC Univ Paris 06, CNRS, Collège de France, 11 place Marcelin Berthelot, 75005 Paris, France \\ ${ }^{c}$ Laboratoire de dynamique, interactions et réactivité (LADIR) UMR 7075, 2 rue Henry Dunant 94320 Thiais, France \\ dUniversité de Poitiers, Département de physique et mécanique des matériaux, Institut P' UPR 3346, Boulevard Marie et Pierre Curie, BP 30179, \\ F86962 Futuroscope Chasseneuil Cedex, France

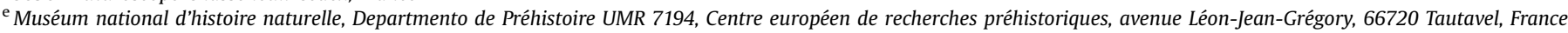

Keywords:

Length-fast chalcedony

Flint

Heat treatment

Annealing

Hydroxyl

Silanole

Porosity

\begin{abstract}
A B S T R A C T
The early occurrence of intentional heat treatment of silica rocks has recently become a key element in the discussion about the cultural modernity of prehistoric populations. Lithic vestiges are the only sources that remain of this process and the understanding of the material's properties and transformations are essential for reconstructing the conditions and parameters applied during heat treatment. Several models of the structural transformations upon heating have been proposed in the current literature. These models are often contradictory and do not account for the most recent structural and mineralogical data on chalcedony. In order to propose a new model, we elaborated an experimental procedure and applied different techniques involving infrared spectroscopy, solid state NMR, X-ray diffraction and electron microscopy. The results show that the major transformation to happen is the loss of silanole $(\mathrm{SiOH})$ and the creation of new $\mathrm{Si}-\mathrm{O}-\mathrm{Si}$ bonds according to the reaction: $\mathrm{Si}-\mathrm{OH} \mathrm{HO}-\mathrm{Si} \rightarrow \mathrm{Si}$ $-\mathrm{O}-\mathrm{Si}+\mathrm{H}_{2} \mathrm{O}$. This reaction starts between $200{ }^{\circ} \mathrm{C}$ and $300^{\circ} \mathrm{C}$ and causes an increase in the hardness of the rocks. The maximal annealing temperature and the ramp rate are the functions of the ability of the structure to evacuate newly created $\mathrm{H}_{2} \mathrm{O}$ and depend on the size of the specimen and the volume of its porosity. These results also show that the annealing duration at maximum temperature can be relatively short ( $<50 \mathrm{~min}$ ) for a sufficiently large amount of transformation to be accomplished.
\end{abstract}

\section{Introduction}

The occurrence of intentionally heat-treated sedimentary silica rocks in the archaeological records of the upper Palaeolithic and the Neolithic throughout the old and the new world has been discussed since the 1960s (Binder and Gassin, 1988; Bordes, 1969; Crabtree and Butler, 1964). Heated flint was found to be greatly ameliorated for pressure flaking as compared to the not heated material and the knapping quality for blade debitag sequences was shown to benefit from the material's transformation. The Solutreans of the European upper Palaeolithic were long-time thought to be the first to have deliberately heat-treated flint for tool production (Bordes, 1969; Tiffagom, 1998). However, the recent discovery of

\footnotetext{
* Corresponding author.

E-mail address: schmidt@mnhn.fr (P. Schmidt).
}

intentionally transformed silcrete from the Middle Stone Age of South Africa (Brown et al., 2009; Mourre et al., 2010) has included this process of transformation in the discussion about cultural modernity of early hunter-gatherers. In order to reconstruct the conditions and parameters applied during heat treatment (i.e. temperature, procedure, heating structure, heating rate and duration), it appear necessary to understand the physical and chemical processes that cause the rock's transformation. Several authors have addressed this issue by proposing models of these transformations.

Secondary minerals like iron oxides that envelope the quartz grains were discussed to increase the coherence of the structure after annealing (Purdy and Brooks, 1971; Schindler et al., 1982). However, successful heat treatment of relatively pure chalcedony that does not contain this type of impurities indicates that the reason for the transformations must be looked for elsewhere. Other authors proposed internal fracturing, occurring during heating, to 
cause homogenisation of the material (Flenniken and Garrison, 1975). This theory could be confuted through the observation that only a reduction of porosity favours a better knapping quality (Patterson, 1984; Patterson and Sollberger, 1979), whereas internal fracturing causes irregular fracture propagation. An interesting model was proposed by Griffiths et al. (1987) who propose the migration of water within the rocks to ameliorate the knapping quality. Although this explanation is based upon a model of water integration in flint (Micheelsen, 1966) that is largely refuted today (Flörke et al., 1982; Graetsch et al., 1985), the role of water appears nonetheless very useful for explaining the heat-induced transformations in silica rocks. Another model proposes recrystallisation to be the cause of the mechanical transformations in flint (Domanski et al., 2009; Domanski and Webb, 1992). Recrystallisation during such short time spans, as they are common for heat treatment, appears unlikely and will be tested for on the following pages.

None of these models is in accordance with the most recent crystallographic and structural data on chalcedony and, in light of the most recent discoveries in South Africa, it appears necessary to propose a new model. The dynamic dehydration behaviour of sedimentary chalcedony was recently shown to be complicated (Schmidt et al., 2011). This process, however, may well account for the major structural transformations upon heating and it seems interesting to discuss its implications for the mechanical transformations of heat-treated archaeological silica rocks. We propose here a new model of the heat-induced transformations of flint that are based on results from X-ray powder diffraction, infrared spectroscopy, Magic Angle Spinning Nuclear Magnetic Resonance (MAS NMR) spectroscopy, Thermogravimetric analysis and material hardness.

\section{Materials and methods}

Five samples of sedimentary silicifications underwent experimental heat treatment at different temperatures and were analysed by means of different techniques. Annealing temperatures, sample numbers and descriptions are summarised in Table 1.

All studied samples consisted entirely of length-fast (LF) sedimentary chalcedony, a fibrous arrangement of nanometre sized $\alpha$ quartz crystallites (Flörke, 1967; Michel-Levy and Munier-Chalmas, 1892; Rios et al., 2001). Four of the five samples are flint, a silica rock formed in Cretaceous chalk deposits (Fröhlich, 2006; Füchtbauer, 1988).

\subsection{Experimental}

\subsubsection{Scanning electron microscope (SEM)}

In order to evaluate the occurrence of recrystallisation during annealing, one sample of Cretaceous flint (LC-S-628) and a sample of a Miocene continental silicification (LC-S-430) were cut into slabs and polished on one side. The polished surface was then etched in hydrofluoric acid (HF) for $3 \mathrm{~min}$ and a thin layer of carbon was deposited. A representative zone was observed in a TESCAN VEGA SEM at different magnifications. The two slabs were then heat treated to $450{ }^{\circ} \mathrm{C}$ during $6 \mathrm{~h}$ with a ramp speed and a cooling rate of $2{ }^{\circ} \mathrm{C} / \mathrm{min}$. The etched surfaces were again coated with a carbon layer and the same zones were observed. In the event of recrystallisation, the surface should appear modified after heat treatment.

\subsubsection{X-ray powder diffraction (XRD)}

Two samples of Upper Cretaceous flint (TR-S-01 and GP-S-01) were broken into pieces. Each piece was heated to a different temperature during $6 \mathrm{~h}$ with a ramp speed and a cooling rate of $2{ }^{\circ} \mathrm{C} / \mathrm{min}$ (for temperatures see Table 1 ). The pieces were then ball milled and sieved with a mesh width of $40 \mu \mathrm{m}$. Average particle size was estimated to $\approx 4 \mu \mathrm{m}$ using a light microscope. Powder diffractograms were recorded between $2 \theta=2^{\circ}$ and $80^{\circ}$ using a PANalytical X'Pert Pro MPD diffractometer (using the $\mathrm{K}_{\alpha}$ line of a $\mathrm{Cu}$ anode, no incident beam monochromator). The sample holder was in constant rotation during the analysis. Each powder was subdivided into three aliquots, each of which was analysed separately. The presented results here correspond to the average of the three analyses. Crystal size was calculated using the Scherrer equation, internal strain was calculated using the Williamsons-Hall method. Both methods are based on the principle that small crystallites and internal strain cause line broadening of the diffraction peaks (Guinebretière, 2007). Used peaks angles $2 \theta$ were $20.7^{\circ}$ (1010);

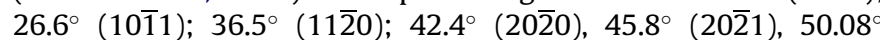
$(11 \overline{2} 2) ; 59.9^{\circ}(21 \overline{3} 1) ; 73.4^{\circ}(10 \overline{1} 4)$ and $75.5^{\circ}(30 \overline{3} 2)$.

\subsubsection{Near infrared spectroscopy (NIR)}

The total content of molecular water and silanole after heat treatment was measured using the NIR combination bands near $4500 \mathrm{~cm}^{-1}(\mathrm{SiOH})$ and $5220 \mathrm{~cm}^{-1}\left(\mathrm{H}_{2} \mathrm{O}\right)$. The samples were cut into sections and diamond polished on both sides (thickness: TR-S$01=792 \pm 5 \mu \mathrm{m}, \mathrm{GP}-\mathrm{S}-01=779 \pm 5 \mu \mathrm{m})$. The sections underwent heat treatment to successive temperatures (Table 1). Spectra were acquired after each heating step in the sample's hydrated and dehydrated states (i.e. containing molecular water in their open porosity or not). A precise description and a discussion of the validity of this experimental protocol can be found in Schmidt et al. (2011). By means of this protocol, we analysed the contents of (1) $\mathrm{SiOH}$, (2) strongly retained $\mathrm{H}_{2} \mathrm{O}$ in the structure and (3) loosely held $\mathrm{H}_{2} \mathrm{O}$ in open pores $\left(\mathrm{H}_{2} \mathrm{O}_{\text {pores }}\right)$. The silanole content can be determined using the absorbance of the $\mathrm{SiOH}$ combination band at $\approx 4500 \mathrm{~cm}^{-1}$ of spectra acquired in the dehydrated state. Strongly retained water can be measured through the $\mathrm{H}_{2} \mathrm{O}$ combination band at $\approx 5200 \mathrm{~cm}^{-1}$ of spectra acquired in the dehydrated state and the content of $\mathrm{H}_{2} \mathrm{O}_{\text {pores }}$ can be determined by subtracting the absorbance of the $\mathrm{H}_{2} \mathrm{O}$ combination band in the dehydrated state

Table 1

Sample descriptions and annealing temperatures.

\begin{tabular}{|c|c|c|c|}
\hline Technique & $\begin{array}{l}\text { Sample } \\
\text { number }\end{array}$ & Description & Annealing temperature $\left[{ }^{\circ} \mathrm{C}\right]$ \\
\hline SEM & LC-S-628 & $\begin{array}{l}\text { Upper Cretaceous flint, entirely Length-fast (LF) chalcedony. } \\
\text { Surroundings of Obourg, Belgium. Collection Cayeux (MNHN). }\end{array}$ & Not heated, 450 \\
\hline SEM & LC-S-430 & $\begin{array}{l}\text { Miocene continental silicification, LF-chalcedony and macro-quartz. } \\
\text { Surroundings of Nanterre. France. Collection Cayeux (MNHN). }\end{array}$ & Not heated, 450 \\
\hline $\begin{array}{l}\text { XRD, NMR, } \\
\text { TG, NIR }\end{array}$ & TR-S-01 & $\begin{array}{l}\text { Turonian flint, entirely LF-chalcedony. North of Tours, France. } \\
\text { Thickness of the NIR section } 792 \mu \mathrm{m} \text {. }\end{array}$ & $\begin{array}{l}110,150,200,250,300 \\
350,400,450,500,550,600\end{array}$ \\
\hline XRD, TG, NIR & GP-S-01 & $\begin{array}{l}\text { Reddish brown Turonian flint, entirely LF-chalcedony. } \\
\text { Le Grand Pressigny, France. Thickness of the NIR section } 779 \mu \mathrm{m} \text {. }\end{array}$ & $\begin{array}{l}110,150,200,250 \\
300,350,400,450,500,550,600\end{array}$ \\
\hline TG & PS-09-04 & Coniacian black flint, entirely LF-chalcedony. Étretat, France. & $40-1000$ continuous \\
\hline
\end{tabular}


from the band in the hydrated state. A more detailed description of this protocol is given in Schmidt et al. (2011).

\subsubsection{MAS NMR}

Data obtained by IR spectroscopy were verified by solid state ${ }^{1} \mathrm{H}$ MAS NMR. Five of the sample powders of TR-S-01, used for the XRD analyses, were analysed at room temperature using a Bruker Avance III $300 \mathrm{Mhz}$ (7.04 T) spectrometer (unheated, $250^{\circ} \mathrm{C}, 300^{\circ} \mathrm{C}, 400^{\circ} \mathrm{C}$ and $500^{\circ} \mathrm{C}$ ). Hundred milligrams of each sample were analysed in a $4 \mathrm{~mm} \mathrm{ZrO}_{2}$ rotor, rotating at $14 \mathrm{kHz}$ and the chemical shifts $(\delta)$ are reported here relative to tetramethylsilane (TMS). Two pulse sequences were used for evaluating the temperature-dependent behaviour of (1) silanole, (2) $\mathrm{H}_{2} \mathrm{O}$ contained in a multilayer in direct contact with the walls of the porosity and stabilised by $\mathrm{H}$-bonding with surface silanoles $\left(\mathrm{H}_{2} \mathrm{O}_{\mathrm{H} \text {-bond }}\right)$ and (3) free $\mathrm{H}_{2} \mathrm{O}$ that does not form $\mathrm{H}$-bonds with silanole groups. These sequences were a spin echo (Hahn, 1950), and a back-to-back sequence (BABA) (Feike et al., 1996). The adequate relaxation time for the spin echo was experimentally found to be $10 \mathrm{~s}$ so that the assessment of the three types of 'water' can be considered as quantitatively significant. The positions and widths of the $\mathrm{SiOH}$ and $\mathrm{H}_{2} \mathrm{O}_{\mathrm{H} \text {-bond }}$ resonances were first determined in the BABA spectra. These parameters were then set as fixed values in a Pseudo-Voigt deconvolution of the spin echo in order to obtain a quantitative measurement of the intensity of these two resonances. The position and width of free $\mathrm{H}_{2} \mathrm{O}$ were directly determined on the spin echo spectra. Error bars for the measurements were estimated based on the signal/noise ratio of the obtained spectra.

\subsubsection{Thermo-gravimetric analysis (TG)}

The dynamic weight loss upon heating of three samples was determined by means of a SETARAM Setsys Evolution thermo balance (He atmosphere and $130 \mu \mathrm{l} \mathrm{Pt}$ sample holder). Samples were heated from $40^{\circ} \mathrm{C}$ to $1000^{\circ} \mathrm{C}$. Two types of samples were analysed, powders and micro-flakes, each weighing $\approx 50 \mathrm{mg}$ to

Table 2

Temperature-dependent evolution of crystal size as calculated from the Scherrer formula of TR-S-01 and GP-S-01.

\begin{tabular}{lll}
\hline Temperature $\left[{ }^{\circ} \mathrm{C}\right]$ & TR-S-01 size $[\mathrm{nm}]$ & GP-S-01 size $[\mathrm{nm}]$ \\
\hline 30 & 32.4 & 54.8 \\
110 & & 41.6 \\
200 & 34.7 & 55.9 \\
250 & 34.1 & 50.5 \\
300 & 35.1 & 47 \\
350 & 32.3 & 53.1 \\
400 & 33.7 & 78.7 \\
450 & 36.5 & 48.8 \\
500 & 38.5 & 57.5 \\
550 & & 81.8 \\
600 & & 61.2 \\
\hline
\end{tabular}

$80 \mathrm{mg}$. Powders with different particle sizes were prepared by wetgrinding under acetone. The curves of three powder particle sizes (20, 7 and $<2 \mu \mathrm{m})$ were compared with the curve of a micro-flake of PS-09-04 in order to evaluate the role of specific surface area upon the dynamic dehydration behaviour.

\subsubsection{Nano-hardness}

In order to assess the transformations of the mechanical properties of the flint upon heat treatment, one sample was cut into seven plan-parallel slabs that were diamond polished on one side. Each slab was heated to a different temperature (unheated, $200^{\circ} \mathrm{C}$, $250{ }^{\circ} \mathrm{C}, 300^{\circ} \mathrm{C}, 350{ }^{\circ} \mathrm{C}, 400^{\circ} \mathrm{C}$ and $500^{\circ} \mathrm{C}$ ) and the nano-hardness was tested by means of an NHT-CSM nano-indenter. The tests were conducted as follows: maximal load was $3 \mathrm{mN}$, repeated 15 times on each samples. Loading, hold and unloading times were all $30 \mathrm{~s}$. The penetration contact depths were $\approx 300 \mathrm{~nm}$. Hardness data is expressed in Pascal (Pa), corresponding to $\mathrm{N} / \mathrm{m}^{2}$ and error bars in the graphical representations correspond to the standard deviations on 15 tests on the same surface.

\subsubsection{Mid infrared spectroscopy (IR)}

In order to compare the hardness data with the results of the spectroscopic measurements, the reflectance at $555 \mathrm{~cm}^{-1}$ was measured on the seven slabs used for the nano-hardness measurements. The intensity of the band is used for evaluating the formation of new bridging $\mathrm{Si}-\mathrm{O}-\mathrm{Si}$ bonds (Schmidt and Fröhlich, 2011).

\section{Results and discussion}

\subsection{Scanning electron microscope}

The results of the SEM observations are shown in Fig. 1. Fig. 1a and $\mathrm{c}$ shows the samples before heating and Fig. $1 \mathrm{~b}$ and $\mathrm{d}$ shows the samples after annealing at $450{ }^{\circ} \mathrm{C}$. All the observed features remain unchanged upon heat treatment. It appears uncertain if the relief shown in these images corresponds to the limits of the quartz crystallites of the chalcedony or to some arbitrary limit the acid attack stopped at. However, the size of the observed features is the same as the size of the chalcedony's crystallites (50-100 nm: Rios et al., 2001) and a change in crystallinity should be noticeable in the shape of these features. The absence of change indicates the non-occurrence of recrystallisation. Images of larger zones on the fracture surfaces, taken at lower magnifications, do not show structural changes due to recrystallisation either. This result is in contradiction with the structural transformations in heated flint proposed by Domanski and Webb (1992) and Domanski et al. (2009). These authors show SEM images of etched surfaces before and after annealing at $400{ }^{\circ} \mathrm{C}$, illustrating a different aspect before and after heat treatment. The so observed surfaces were etched after cooling to room temperature and do not show the same zone before and after the treatment, thus only illustrating a different response to etching before and after heat treatment. Our images show that this differential resistance to HF is not caused by in situ recrystallisation.

\subsection{X-ray powder diffraction}

Crystallite sizes after heat treatment as calculated from the Scherrer formula are summarised in Table 2. These values are in agreement with previously published data on crystal size in chalcedony (Flörke et al., 1982; Rios et al., 2001). The values increase for both samples with increasing temperature. The evolution of the internal strain of these crystallites is shown in Fig. 2. These graphs suggest a slight increase of the internal strain. However, the values are too scattered to make a clear statement about the evolution. 
Larger crystallites after annealing may suggest recrystallisation. The results of the SEM observations show nonetheless that there must be a different explanation. A possible factor causing an apparent increase in crystallite size as determined through X-ray line broadening is the reduction of crystal defects. The formation of new $\mathrm{Si}-\mathrm{O}-\mathrm{Si}$ bonds upon heat treatment, as previously shown by Schmidt et al. (2011), results from the reduction of water related defects that, before heat treatment, contributed to the broadening of the X-ray peaks.

\subsection{Infrared spectroscopy}

NIR measurements reveal the loss of silanole upon heat treatment from $250{ }^{\circ} \mathrm{C}$ upwards (Fig. 3a). Before heating, the $\mathrm{SiOH}$ concentration in TR-S-01 is $\approx 50 \%$ higher than in GP-S-01 (TR: 0.81 wt\% against GP: 0.38 wt\%). After heat treatment at $500{ }^{\circ} \mathrm{C}$, both samples contain very similar amounts of SiOH (TR: $10 \mathrm{wt} \%$ and GP: $17 \mathrm{wt} \%$ ).

Both, TR-S-01 and GP-S-01 gain $\mathrm{H}_{2} \mathrm{O}$ retained in closed pores from $250{ }^{\circ} \mathrm{C}$ upwards (Fig. 3b). The quantity of newly formed water is larger in TR-S-01 than in GP-S-01 (from $0.38 \mathrm{wt} \%$ before treatment to $0.59 \mathrm{wt} \%$ after annealing at $450{ }^{\circ} \mathrm{C}$ for TR against $0.28 \mathrm{wt} \%$ before treatment to $0.39 \mathrm{wt} \%$ after annealing at $450{ }^{\circ} \mathrm{C}$ for GP). This can be explained by the stronger loss of $\mathrm{SiOH}$, indicating the conversion from silanole to molecular water as previously shown by Schmidt et al. (2011). The $\mathrm{H}_{2} \mathrm{O}$ content of TR-S-01 decreases above $500{ }^{\circ} \mathrm{C}$ (Fig. 3b). This turning point is induced by the beginning of internal fracturing (as determined by macroscopic observations), allowing the evacuation of the trapped water.

Fig. 4a is a plot of the content of water kept in the open porosity of the samples $\left(\mathrm{H}_{2} \mathrm{O}_{\text {pores }}\right)$. Open pores retain $\approx 0.3 \mathrm{wt} \%$ of water before heating. The volume of these pores is rapidly reduced above $200{ }^{\circ} \mathrm{C}$. After heat treatment at $400{ }^{\circ} \mathrm{C}$ the samples are almost pore free.

\subsection{Mid infrared}

The absorption band at $555 \mathrm{~cm}^{-1}$ disappears gradually upon heat treatment, indicating the formation of new $\mathrm{Si}-\mathrm{O}-\mathrm{Si}$ bonds according to the reaction: $\mathrm{Si}-\mathrm{OH} \mathrm{HO}-\mathrm{Si} \rightarrow \mathrm{Si}-\mathrm{O}-\mathrm{Si}+\mathrm{H}_{2} \mathrm{O}$ (Schmidt et al., 2011) (Fig. 4b). The formation of new bridging $\mathrm{Si}-\mathrm{O}-\mathrm{Si}$ begins at $250^{\circ} \mathrm{C}$ and is induced by the loss of silanole (Schmidt and Fröhlich, 2011). The plot in Fig. 4b appears more scattered than the plot of the SiOH content in Fig. 3a. This may be explained by the fact that NIR and mid infrared analyses were done on different samples (one polished $792 \mu \mathrm{m}$ thick section for NIR and 7 slabs with one polished side each for mid IR).

\section{5. ${ }^{1} \mathrm{H}$ MAS NMR}

An example of the Echo and BABA spectra and the deconvoluted

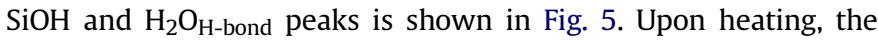
quantities and chemical shifts $(\delta)$ of the $\mathrm{SiOH}, \mathrm{H}_{2} \mathrm{O}$ and $\mathrm{H}_{2} \mathrm{O}_{\mathrm{H} \text {-bond }}$ peaks change. The SiOH peak position shifts to higher values of $\delta$ from $300{ }^{\circ} \mathrm{C}$ upwards (Fig. 6a). Zheng et al. (2007) showed $\delta$ in deuterated pyridine to be dependent of the Brønsted acidity of the proton sites. According to this model, the increase of the SiOH chemical shift indicates a reduction of the acidic strength of the proton environment upon heat treatment. Decreasing acidity of the environment of $\mathrm{SiOH}$ in heat-treated flint may indicate that the free negative charge of a part of the $\mathrm{SiO}^{-}$ions, which formed upon dehydration, remains uncompensated after rehydration. This is most likely the case where $\mathrm{SiO}^{-}$ions are too far from each other to form $\mathrm{Si}-\mathrm{O}-\mathrm{Si}$ bonds and where water cannot penetrate after heat treatment.

The chemical shifts of the two $\mathrm{H}_{2} \mathrm{O}$ peaks decrease upon heating (Fig. $6 \mathrm{~b}$ and c). The ${ }^{1} \mathrm{H}$ chemical shift caused by thin $\mathrm{H}_{2} \mathrm{O}$ multilayers is sensitive to the layer thickness (van der Meer et al., 2010). Thus,

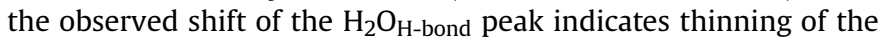
multilayer in direct contact with the walls. In the same way, the shift of the $\mathrm{H}_{2} \mathrm{O}$ peak may indicate the reduction of the bulk volume of $\mathrm{H}_{2} \mathrm{O}$ held in the porosity. These observations are in accordance with the reduction of open porosity as observed through IR spectroscopy. The beginning of the process is more abrupt for free $\mathrm{H}_{2} \mathrm{O}$ than for $\mathrm{H}_{2} \mathrm{O}_{\mathrm{H}-\text { bond, indicating that the multilayer thinning begins }}$ before free $\mathrm{H}_{2} \mathrm{O}$ experiences a reduction and specific surface of the material drops.

The relative percentages of $\mathrm{SiOH}, \mathrm{H}_{2} \mathrm{O}_{\mathrm{H} \text {-bond }}$ and free $\mathrm{H}_{2} \mathrm{O}$ after heating to different temperature are shown in Fig. 7. The conversion of $2 \mathrm{SiOH} \rightarrow \mathrm{Si}-\mathrm{O}-\mathrm{Si}+\mathrm{H}_{2} \mathrm{O}$ is obvious from $250{ }^{\circ} \mathrm{C}$ upwards. As for the IR measurements of the water content (Fig. 3b), the trend shows a turning point at higher temperatures, which is induced by the fracturing of the sample allowing water to be evaporated.

\subsection{Thermo-gravimetric analysis}

Between 1 and $2 \mathrm{wt} \%$ are lost upon heating until $1000^{\circ} \mathrm{C}$. These values are in accordance with the quantitative IR $\mathrm{SiOH}$ and $\mathrm{H}_{2} \mathrm{O}$ determination.

Fig. 8 displays the TG curves of three micro-flakes of PS-09-04 heated at different speeds and their derivatives. The $1{ }^{\circ} \mathrm{C} / \mathrm{min}$ curve shows three dehydration events (Fig. 8b). (1) The first event between 50 and $150{ }^{\circ} \mathrm{C}$ corresponds to the evaporation of $\mathrm{H}_{2} \mathrm{O}$ loosely held in open pores and acetone remaining from the powder preparation. (2) The second event lies between 250 and $500{ }^{\circ} \mathrm{C}$. IR and NMR analyses suggest that this event corresponds to the loss of silanole. (3) The massive event between 550 and $800^{\circ} \mathrm{C}$ corresponds to the loss of water retained in closed pores and is caused by fracturing of the samples. The temperature of this event is higher in slowly heated samples than in rapidly heated ones. The $1^{\circ} \mathrm{C} / \mathrm{min}$ curve shows all three events with the best resolution so that all further TG analyses were executed with this speed.

Fig. 9 is a comparison between the TG curves of different particle sizes of PS-09-04 and their derivatives. It is noteworthy that the $<2 \mu \mathrm{m}$ powder lost $\approx 0.5 \%$ more mass than the larger particle sizes (Fig. 9a). Fig. 9b shows event (3) only for the micro-flake and, to a lesser extent, for the coarsest powder. Event (2) is all the more pronounced in the finer powders. These results indicate that fracturing only occurs if water resulting from the $\mathrm{SiOH} \rightarrow \mathrm{H}_{2} \mathrm{O}$ 
conversion cannot be evacuated immediately after its formation. Smaller particles with higher specific surface areas allow better evacuation of $\mathrm{H}_{2} \mathrm{O}$ through open pores than more voluminous samples with a lower specific surface area. Heating speed is another important variable. At faster heating rates fracturing begins at lower temperatures. Our tests were limited to small samples but the results of Mercieca and Hiscock (2008) suggest that the same is true for larger volumes as they are common in the lithic reduction chain. These authors found that smaller volumes of silcrete can be heated to higher temperatures. Their finding can be explained by the role of water evaporation through open pores.

Fig. 10 is a comparison between the TG curve derivatives of three micro-flakes of three flint samples. The three derivatives show a different morphology of event (2), suggesting that silanole loss starts at different temperatures (between 250 and $300{ }^{\circ} \mathrm{C}$ ) for the 3 samples. GP-S-01 permits a better evacuation of $\mathrm{H}_{2} \mathrm{O}$ than the other 2 samples and experiences less fracturing. The event is subdivided into two peaks, the first one of which is most probably correlated with a rapid SiOH loss of the walls of open pores and the second one with a more continuous loss of silanole and molecular water from less open pores. In samples TR-S-01 and PS-09-04 the evacuation of newly created $\mathrm{H}_{2} \mathrm{O}$ is somewhat hindered and the majority of the mass is only liberated upon fracturing (event (3)). It therefore seems that the diffusion potential of the network of porosity of different samples influences the tolerated heating rate (and consequently the maximal heating temperature). These results may explain why different flint types support heating to different temperatures.

\subsection{Nano-hardness}

The values of the nano-hardness are summarised in Table 3 and the temperature-dependent evolution is graphically shown in Fig. 11a. The hardness increases from $250{ }^{\circ} \mathrm{C}$ upwards. A comparison of these values with the data obtained by the IR reflectance measurements shows the correlation of the two phenomena. Fig. 11b is a superposition of the two plots. The IR data is shown with a reversed coordinate axis for a better comparability. The transformations in both plots begin at the same temperature $\left(250^{\circ} \mathrm{C}\right)$ and show a step-like shape.

This result suggests the formation of new $\mathrm{Si}-\mathrm{O}-\mathrm{Si}$ bonds in heat-treated flint to be the cause of the transformation of the mechanical properties of the rock. These findings are in contradiction with previous studies (Domanski and Webb, 1992; Domanski et al., 1994) of the mechanical properties of heattreated flint that state the hardness to remain unchanged. These authors found decreasing fracture toughness to be the most significant transformation in flint upon heat treatment. We expect a correlation between nano-hardness and the fracture toughness of the material. Further analyses are currently being prepared.

\section{A new model of the structural transformations that occur during heat treatment}

These results allow for a better understanding of the nature of the transformations that occur during heat treatment of flint. We therefore propose a new model describing these processes as a function of temperature, heating rate and duration.

\subsection{The transformations}

The SEM observations before and after heat treatment at $450{ }^{\circ} \mathrm{C}$, demonstrate the absence of recrystallisation. The powder diffraction data, however, indicate a transformation of the chalcedony.
What are the processes that reduce line broadening during heating and suggest an increase in crystal size? The breadth of diffraction peaks is influenced by various factors, such as size, strain and crystal defects (Guinebretière, 2007).

Our IR and NMR measurements suggest the major heat-induced transformations to be the loss of $\mathrm{H}_{2} \mathrm{O}$ and $\mathrm{SiOH}$. Heating causes the separation of $\mathrm{H}^{+}$protons from surface silanols on pore walls, creating negative charges in the form of $\mathrm{Si}-\mathrm{O}^{-}$ions. Where these pores have a volume large enough to allow the re-penetration of atmospheric water after cooling, the negative charges can be compensated by integrating new $\mathrm{H}^{+}$protons, restoring the state before the heating. Where these pore walls are close enough to allow interaction between the $\mathrm{Si}-\mathrm{O}^{-}$ions of opposite walls, $\mathrm{Si}-\mathrm{O}-\mathrm{Si}$ bonds are formed according to the reaction:

$$
\mathrm{Si}-\mathrm{OH} \mathrm{HO}-\mathrm{Si} \rightarrow \mathrm{Si}-\mathrm{O}-\mathrm{Si}+\mathrm{H}_{2} \mathrm{O}
$$

This reaction leads to the creation of water molecules, a part of which can be evacuated though open pores (causing the observed TG weight losses: Flörke et al., 1982; Graetsch et al., 1985; Pelto, 1956). IR measurements show the drastic reduction of the volume of these pores (Fig. 4a) (up to $99 \%$ of the water absorbing pore volume is reduced upon heat treatment of some samples). The reduction of the volume of open pores is schematically shown in Fig. 12.

However, not only the pore walls are covered with silanole. A considerable amount of $\mathrm{SiOH}$ is located within the crystallites (Graetsch et al., 1985), most likely at defect sites resulting from the high density of Brazil twin interfaces (Flörke et al., 1982; Miehe et al., 1984). McLaren et al. (1983) suggest that internal surfaces, in association with Brazil twin interfaces contain a significant amount of $\mathrm{SiOH}$. The formation of new $\mathrm{Si}-\mathrm{O}-\mathrm{Si}$ bonds at these crystal defects results in the creation of $\mathrm{H}_{2} \mathrm{O}$ molecules that cannot easily be evacuated. If the conversion $\mathrm{SiOH} \rightarrow \mathrm{H}_{2} \mathrm{O}$ continues, it can be expected that the water molecules form liquid inclusions. IR measurements of the $\mathrm{H}_{2} \mathrm{O}$ concentration show this increase of water in closed pores (Fig. 3b). The reduction of water related defects within the structure may also explain the powder diffraction results, for the described crystal defects contribute to the line broadening. Our measurements indicate a good correlation between the formation of new $\mathrm{Si}-\mathrm{O}-\mathrm{Si}$ bonds and the increase in nano-hardness. A material's hardness is correlated with other mechanical properties such as fracture toughness (Le Bourhis, 2008) and it appears likely that the observed chemical reaction is responsible for changes in the mechanical properties of flint.

SEM observations of fracture surfaces show that after heat treatment, the removal of a flake produces a smoother surface (Olausson and Larsson, 1982; Purdy and Brooks, 1971). This phenomenon can be explained by the loss of silanole and the formation of new $\mathrm{Si}-\mathrm{O}-\mathrm{Si}$ bonds. In unheated material, defects, dislocations and pores are micrometre sized predetermined breaking points. A shock wave running through the rock can be offset or partially damped at these discontinuities. Defect and pore reduction can be understood as homogenisation of the rock. A supplementary confirmation of this comes from Patterson and Sollberger (1979) who present an experimental study using flint soaked in water for several days. Their water treatment, i.e. water filling the voids in the rock (open porosity), allows for a better transmission of the forces, improving the knapping quality of the

Table 3

Results of the nano-hardness measurements.

\begin{tabular}{lrrrrrrr}
\hline Temperature $\left[{ }^{\circ} \mathrm{C}\right]$ & 100 & 200 & 250 & 300 & 350 & 400 & 500 \\
\hline Nano-hardness [GPa] & 11.3 & 11.1 & 11.9 & 11.9 & 12.3 & 12.1 & 12.7 \\
Standard deviation & 0.6 & 0.8 & 0.8 & 0.8 & 0.5 & 1.0 & 1.0 \\
\hline
\end{tabular}


studied flint. In the case of heat treatment, reducing pores and discontinuities has a similar or even more pronounced effect. After heating, the fracture passes through the material more directly, without being offset or damped by pores and crystal defects. This homogenisation results in the smoother fracture surfaces observed by SEM and the greasy lustre observed macroscopically.

\subsection{Annealing temperatures and heating rates}

Which is the range of temperatures useful for thermal treatment of flint? Our IR analysis and the work of Schmidt et al. (2011) indicate the loss of silanole to begin between $200^{\circ} \mathrm{C}$ and $300^{\circ} \mathrm{C}$ for different samples. Thus, heat treatment below $200{ }^{\circ} \mathrm{C}$ does not have any effect.

The maximal temperature for the treatment depends on the beginning of internal fracturing. Samples prepared for the IR analyses experience internal fracturing from $450^{\circ} \mathrm{C}$ upwards (Schmidt et al., 2011). However, our TG analyses show that the beginning of internal fracturing depends on the volume of the samples (i.e. their specific surface). Coarse-grained powders and micro-flakes fracture at relatively low temperatures whereas the finer powders begin fracturing at higher temperatures. This can be explained by the mechanism causing the fracturing: the conversion from $\mathrm{SiOH} \rightarrow \mathrm{H}_{2} \mathrm{O}$. Water that cannot be evacuated is trapped in liquid inclusions. The vapour pressure in this liquid inclusions increases at higher temperatures (Burnham et al., 1969), eventually causing internal fracturing of the rock. Some of the liquid inclusions lie close to pores and their water can be slowly evacuated through the network of open porosity. Due to the small diameter of the pores, the diffusion rate can be expected to be rather small. The evacuation of the water content is therefore faster for small volumes than for larger ones in which the water from the centre has to pass a longer distance before reaching the surface. Water "on its way" to the surface contributes to the vapour pressure and, hence to the beginning of internal fracturing.

The same is true for the heating rate that has to be slower for larger volumes than for smaller ones. Water must have sufficient time to be evacuated from the structure before reaching the next higher temperature. The heat consumed by the ongoing reaction is yet another factor requiring slow heating rates. The $(\mathrm{SiOH})_{2} \rightarrow \mathrm{Si}-\mathrm{O}-\mathrm{Si}+\mathrm{H}_{2} \mathrm{O}$ reaction begins between $200{ }^{\circ} \mathrm{C}$ and $300^{\circ} \mathrm{C}$. Whereas the temperature outside of the sample continues to rise, the inside remains cooler due to the chemical reaction consuming heat. The temperature inside can only climb to reach the outside temperature when the reaction is complete. There is a temperature difference between outside and inside the sample that is more important than the temperature gradient in a chemically inert material. This temperature difference may lead to heterogeneous dilatation contributing to internal fracturing if the heating rate is too fast.

The cooling rate, on the other hand, can be faster than the heating rate. Upon cooling, the vapour pressure in the rock is released and the risk of fracturing decreases successively. The sole limit to the cooling rate's speed is to avoid fracturing caused by heterogeneous dilatation in the material.

These considerations may explain the results of Mercieca and Hiscock (2008) who stress that smaller volumes can be heated to higher temperatures than larger ones. The heating of large cores of flint, as assumed for the Neolithic culture of the Chasséen (Binder and Gassin, 1988; Léa, 2004), requires the maximum annealing temperature to remain relatively low and the heating rate to be very slow.

Thus, the ideal temperatures for heat treatment seem to be between $200^{\circ} \mathrm{C}$ and $450^{\circ} \mathrm{C}$ depending on the nature of the samples and the state of their porosity. A flint sample heated to $400{ }^{\circ} \mathrm{C}$ is more homogenous and shows more intense transformations of its mechanical properties than a sample heated to $250^{\circ} \mathrm{C}$. However, the maximal temperature is limited by the beginning of internal fracturing that reduces knapping quality. Hence, the ideal temperature for heat treatment is a compromise between the interests of producing intense enough transformations and the prevention of accidental fractures. It depends on the volume of rock but also on the volume of its porosity and the concentration of silanole.

\subsection{Annealing time}

Fukuda and Nakashima (2008) found that the loss of silanole at high temperatures is essentially terminated after annealing for 50 min. Thus, maintaining a sample at the maximum temperature of the heat treatment for $50 \mathrm{~min}$ is sufficient for the transformations in the material to be accomplished. A more intense transformation of the flint's properties can only be achieved by raising the maximum heating temperature. Between 0 and $50 \mathrm{~min}$, the $\mathrm{SiOH}$ loss is a negative exponential distribution (Fukuda and Nakashima, 2008), indicating that much of the reaction is already finished after the first minutes of annealing. These results suggest that heat treatment of a few minutes at maximum temperature is enough for much of the transformation to be accomplished and the properties of the flint to be transformed. However, this time does not include the ramp rate at which the sample has to be brought to the maximum temperature (i.e. the total time of the heat treatment). As discussed in Section 4.2, this ramp rate is a function of the sample's volume, porosity and silanole content.

\section{Conclusion}

This new model of the transformations of LF-chalcedony upon annealing creates a new understanding of the processes that occur in heated flint. Beyond its interest for Materials Science, the model allows for the assessment of the behaviour of prehistoric men during the process of heat treatment. The understanding of heating conditions such as annealing time, maximum temperature or heating rate is indispensable for the study of the behaviour of the heat treatment's authors. For example, heating a rock to a precise temperature between 200 and $450{ }^{\circ} \mathrm{C}$ requires a good control of the heating structures and illustrates the knowledge of fire and its properties. Likewise, the necessity of a slow heating rate for larger volumes of flint may require the executor to build elaborated structures to avoid rapid heating. The identification of the process by which these transformations occur will also allow for more target-oriented experimentations. Thus, the understanding of the chemical reaction that causes the flint's transformation and its kinetics is a factor in the study of the conditions and environments of archaeological lithic heat treatment.

This model applies to all silica rocks containing LF-chalcedony, including flint and different chert varieties. It does also apply to silicifications made up of other types of chalcedony such as Magadi chert (Length-slow chalcedony) and most types of radiolarian jasper (mostly microquartz). Although the processes in these materials are very similar, preliminary results suggest the maximum temperatures and heating rates to differ from LFchalcedony. Further tests are currently being run on these materials. In the light of the most recent findings of heat treatment traces in South Africa (Middle Stone Age) (Brown et al., 2009; Mourre et al., 2010), the validity of this model for South African silcrete becomes increasingly interesting. The case of these silcretes, however, has to be discussed separately, for their mineralogy, structure and silanol content differ from flint and marine cherts. Experiments on this material are currently being conducted. 


\section{Acknowledgements}

We thank Thibaud Saos from the Centre Européen de Recherches Préhistoriques de Tautavel (CERP) for his collaboration to the acquisition of the X-ray powder diffraction data used in this work.

\section{References}

Binder, D., Gassin, B., 1988. Le débitage laminaire chasséen après chauffe: technologie et traces d'utilisation. In: Beyries, S. (Ed.), Industries lithiques, tracéologie et technologie. British Archaeological Reports, Oxford, pp. 93-125.

Bordes, F., 1969. Traitement thermique du silex au Solutréen. Bulletin de la Société préhistorique française 66, 197.

Brown, K.S., Marean, C.W., Herries, A.I.R., Jacobs, Z., Tribolo, C., Braun, D. Roberts, D.L., Meyer, M.C., Bernatchez, J., 2009. Fire as an engineering tool of early modern humans. Science $325,859-862$.

Burnham, C., Holloway, J., Davis, N., 1969. Thermodynamic Properties of Water to $1,000^{\circ} \mathrm{C}$ and 10,000 bars. Geological Society of America, Boulder

Crabtree, D.E., Butler, B.R., 1964. Notes on experiment in flint knapping: 1 heat treatment of silica materials. Tebiwa 7, 1-6.

Domanski, M., Webb, J., Glaisher, R., Gurba, J., Libera, J., Zakoscielna, A., 2009. Heat treatment of Polish flints. Journal of Archaeological Science 36, 1400-1408.

Domanski, M., Webb, J.A., 1992. Effect of heat treatment on siliceous rocks used in prehistoric lithic technology. Journal of Archaeological Science 19, 601-614.

Domanski, M., Webb, J.A., Boland, J., 1994. Mechanical properties of stone artefact materials and the effect of heat treatment. Archaeometry 36, 177-208.

Feike, M., Demco, D.E., Graf, R., Gottwald, J., Hafner, S., Spiess, H.W., 1996. Broadband multiple-quantum NMR spectroscopy. Journal of Magnetic Resonance, Series A 122, 214-221.

Flenniken, J.J., Garrison, E.G., 1975. Thermally altered novaculite and stone tool manufacturing techniques. Journal of Field Archaeology 2, 125-131.

Flörke, O.W., 1967. Die Modifikationen von SiO2. Fortschritte der Mineralogie 44 $181-230$.

Flörke, O.W., Köhler-Herbertz, B., Langer, K., Tönges, I., 1982. Water in microcrystalline quartz of volcanic origin: Agates. Contributions to Mineralogy and Petrology 80, 324-333.

Fröhlich, F., 2006. Silex et Cherts: Questions de Genèse. Bulletin d'information des Géologues du Bassin de Paris 43, 5-22.

Füchtbauer, H., 1988. Sedimente und Sedimentgesteine, fourth ed. Schweizerbart, Stuttgart.

Fukuda, J., Nakashima, S., 2008. Water at high temperatures in a microcrystalline silica (chalcedony) by in-situ infrared specroscopy: physicochemical states and dehydration behavior. Journal of Mineralogical and Petrological Sciences 103, $112-115$.

Graetsch, H., Flörke, O.W., Miehe, G., 1985. The nature of water in chalcedony and opal-C from brazilian agate geodes. Physics and Chemistry of Minerals 12, 300-306.

Griffiths, D.R., Bergman, C.A., Clayton, C.J., Ohnuma, K., Robins, G.V., 1987. Experimental investigation of the heat treatment of flint, in: Sieveking, G.d.G., Newcomer, M.H. (Eds.), The Human Uses of Flint and Chert. Proceedings of the
Fourth International Flint Symposium Held at Brighton Polytechnic 10-15 April 1983, Cambridge University Press, Cambridge, pp. 43-52.

Guinebretière, R., 2007. X-ray Diffraction by Polycrystalline Materials. WileyBlackwell, Portland.

Hahn, E.L., 1950. Spin echoes. Physical Review 80, 580.

Le Bourhis, E., 2008. Glass Mechanics and Technology. Wiley, Weinheim.

Léa, V., 2004. Centres de production et diffusion des silex bédouliens au Chasséen. Gallia préhistoire 46, 231-250.

McLaren, A.C., Cook, R.F., Hyde, S.T., Tobin, R.C., 1983. The mechanisms of the formation and growth of water bubbles and associated dislocation loops in synthetic quartz. Physics and Chemistry of Minerals 9, 79-94.

Mercieca, A., Hiscock, P., 2008. Experimental insights into alternative strategies of lithic heat treatment. Journal of Archaeological Science 35, 2634-2639.

Micheelsen, H., 1966. The structure of dark flint from Stevns, Denmark. Meddelesse fra Dansk Geologisk Forening 16, 285-368.

Michel-Levy, A., Munier-Chalmas, C.P.E., 1892. Mémoire sur les diverses formes affectées par le réseau élémentaire du quartz. Bulletin de la société minéralogique de France 7, 159-195.

Miehe, G., Graetsch, H., Flörke, O.W., 1984. Crystal structure and growth fabric of length-fast chalcedony. Physics and Chemistry of Minerals 10, 197-199.

Mourre, V., Villa, P., Henshilwood, C.S., 2010. Early use of pressure flaking on lithic artifacts at Blombos Cave, South Africa. Science 330, 659-662.

Olausson, D.S., Larsson, L., 1982. Testing for the presence of thermal pretreatment of flint in the mesolithic and neolithic of Sweden. Journal of Archaeological Science 9, 275-285.

Patterson, L.W., 1984. Comments on studies of thermal alteration of Central Pennsylvania Jasper. American Antiquity 49, 168-173.

Patterson, L.W., Sollberger, J.B., 1979. Water treatment of flint. Lithic Technology 8 50-51.

Pelto, C.R, 1956. A study of chalcedony. American Journal of Science 254, 32-50.

Purdy, B.A., Brooks, H.K., 1971. Thermal alteration of silica minerals: an archeological approach. Science 173, 322-325.

Rios, S., Salje, E.K.H., Redfern, S.A.T., 2001. Nanoquartz vs. macroquartz: a study of the a $-\beta$ phase transition. The European Physical Journal B 20, 75-83.

Schindler, D.L., Hatch, J.W., Hay, C.A., Bradt, R.C., 1982. Aboriginal thermal alteration of a Central Pennsylvania Jasper: analytical and behavioral implications. American Antiquity 47, 526-544.

Schmidt, P., Badou, A., Fröhlich, F., 2011. Detailed FT near-infrared study of the behaviour of water and hydroxyl in sedimentary length-fast chalcedony, $\mathrm{SiO}_{2}$ upon heat treatment. Spectrochimica Acta Part A: Molecular and Biomolecula Spectroscopy 81, 552-559.

Schmidt, P., Fröhlich, F., 2011. Temperature dependent crystallographic transformations in chalcedony, $\mathrm{SiO}_{2}$, assessed in mid infrared spectroscopy. Spectrochimica Acta Part A: Molecular and Biomolecular Spectroscopy 78, 1476-1481.

Tiffagom, M., 1998. Témoignages d'un traitement thermique des feuilles de laurier dans le Solutréen supérieur de la grotte du Parpalló (Gandia, Espagne). Paléo, 147-161.

van der Meer, J., Bardez-Giboire, I., Mercier, C., Revel, B., Davidson, A. Denoyel, R., 2010. Mechanism of metal oxide nanoparticle loading in SBA-15 by the double solvent technique. Journal of Physical Chemistry C 114 3507-3515.

Zheng, A., Zhang, H., Chen, L., Yue, Y., Ye, C., Deng, F., 2007. Relationship between 1H chemical shifts of deuterated pyridinium ions and brønsted acid strength of solid acids. Journal of Physical Chemistry B 111, 3085-3089. 

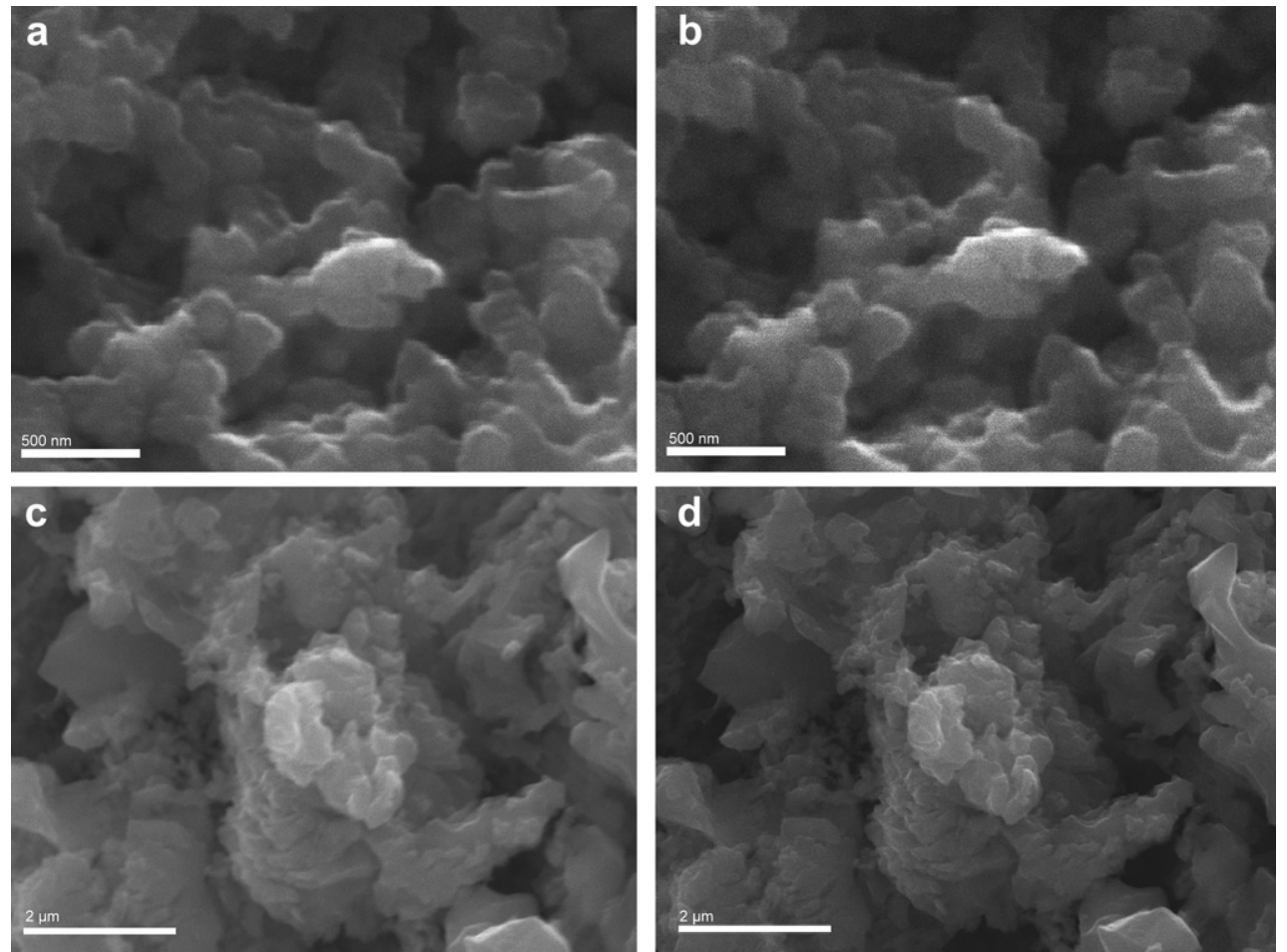

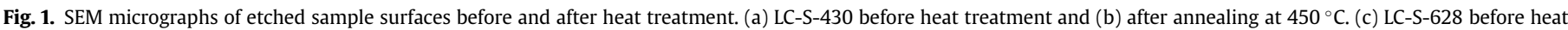

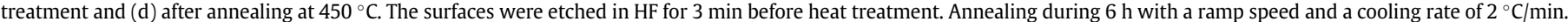
The comparison of the micrographs before and after heating reveals the absence of recrystallisation.

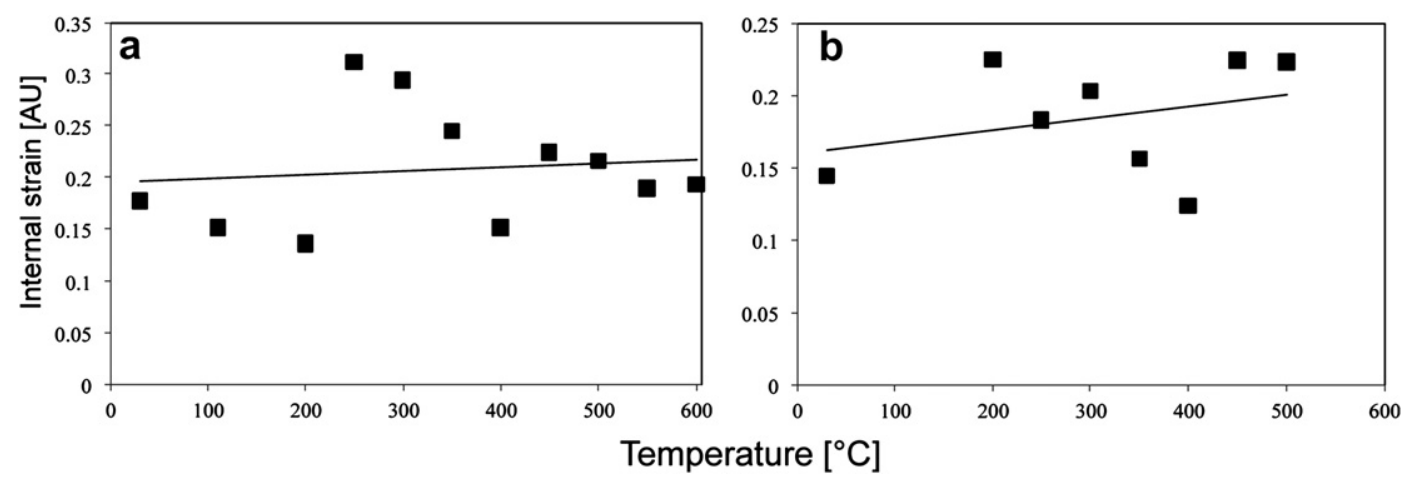

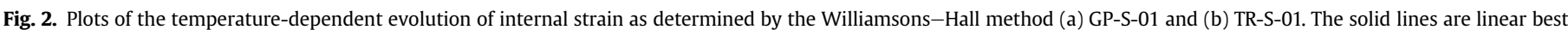
fits: (a) $R^{2}=0.013$ and (b) $R^{2}=0.095$. These graphs suggest a slight increase of the internal strain.
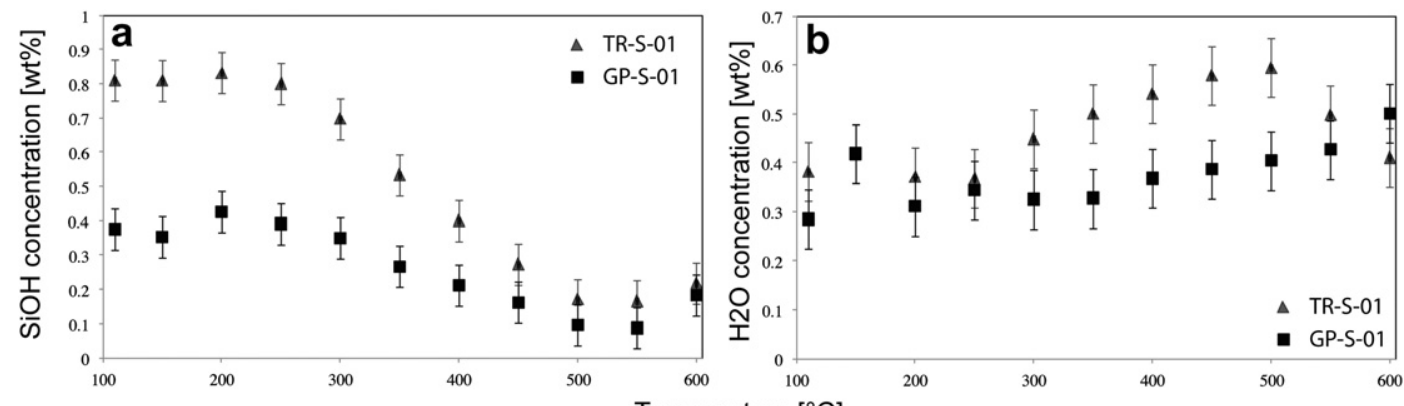

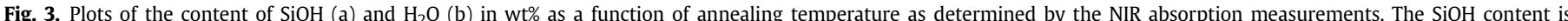

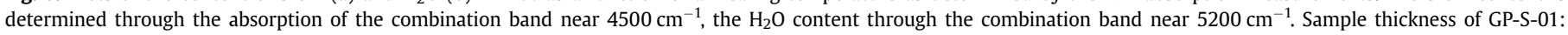
$779 \mu \mathrm{m}$, TR-S-01: $792 \mu \mathrm{m}$. Error bars were determined by repeating the measurement several times for one sample. 


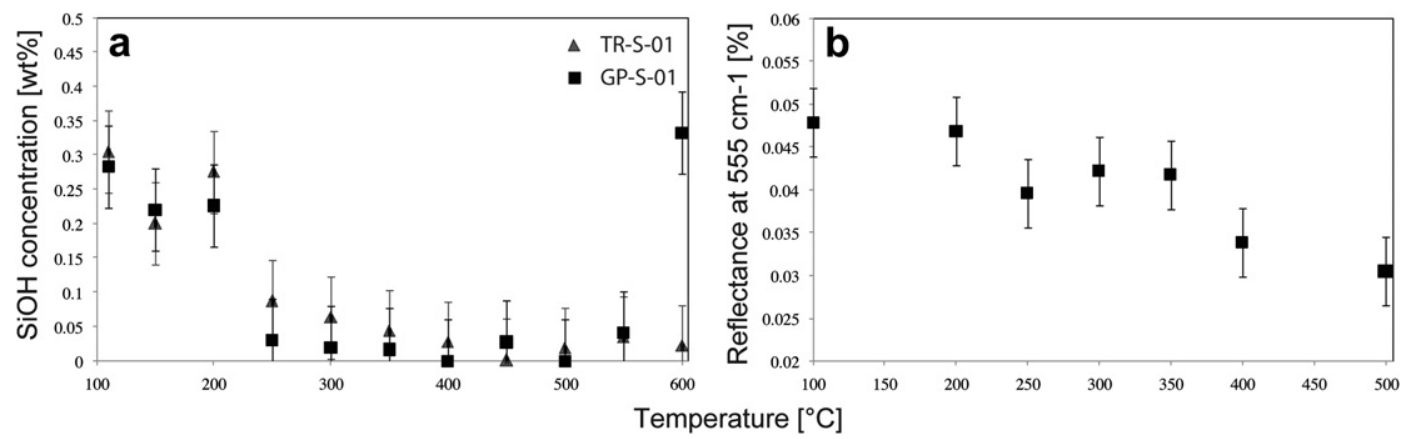

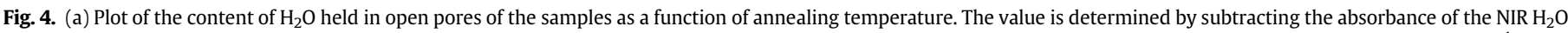

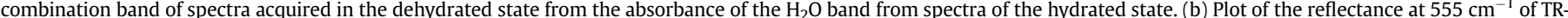

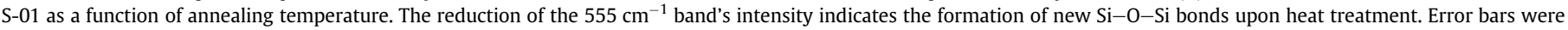
determined by repeating the measurement several times for one sample.

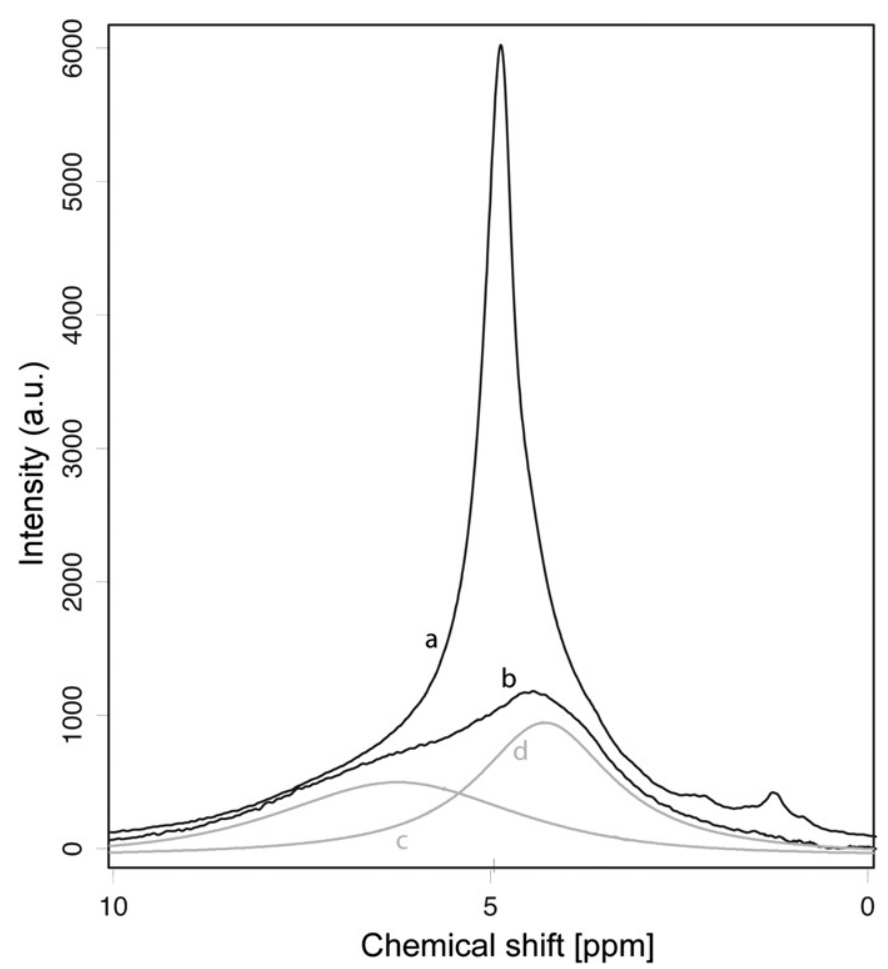

Fig. 5. ${ }^{1} \mathrm{H}$ MAS NMR spectra of the unheated sample TR-S-01. (a) Spin echo, (b) BABA, (c) $\mathrm{SiOH}$ peak as determined by the deconvolution of the BABA spectrum and (d) $\mathrm{H}_{2} \mathrm{O}$ multilayer peak as determined by the deconvolution of the BABA spectrum.

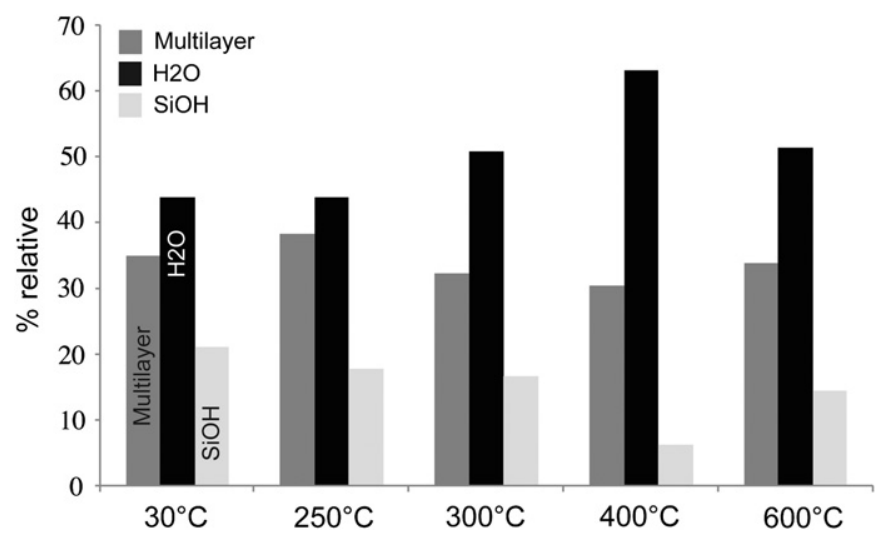

Fig. 7. Relative percentages of $\mathrm{SiOH}$, the $\mathrm{H}_{2} \mathrm{O}$ multilayer and free $\mathrm{H}_{2} \mathrm{O}$ as a function of annealing temperature. The histogram illustrates the conversion of $\mathrm{SiOH} \rightarrow \mathrm{H}_{2} \mathrm{O}$ upon heat treatment.
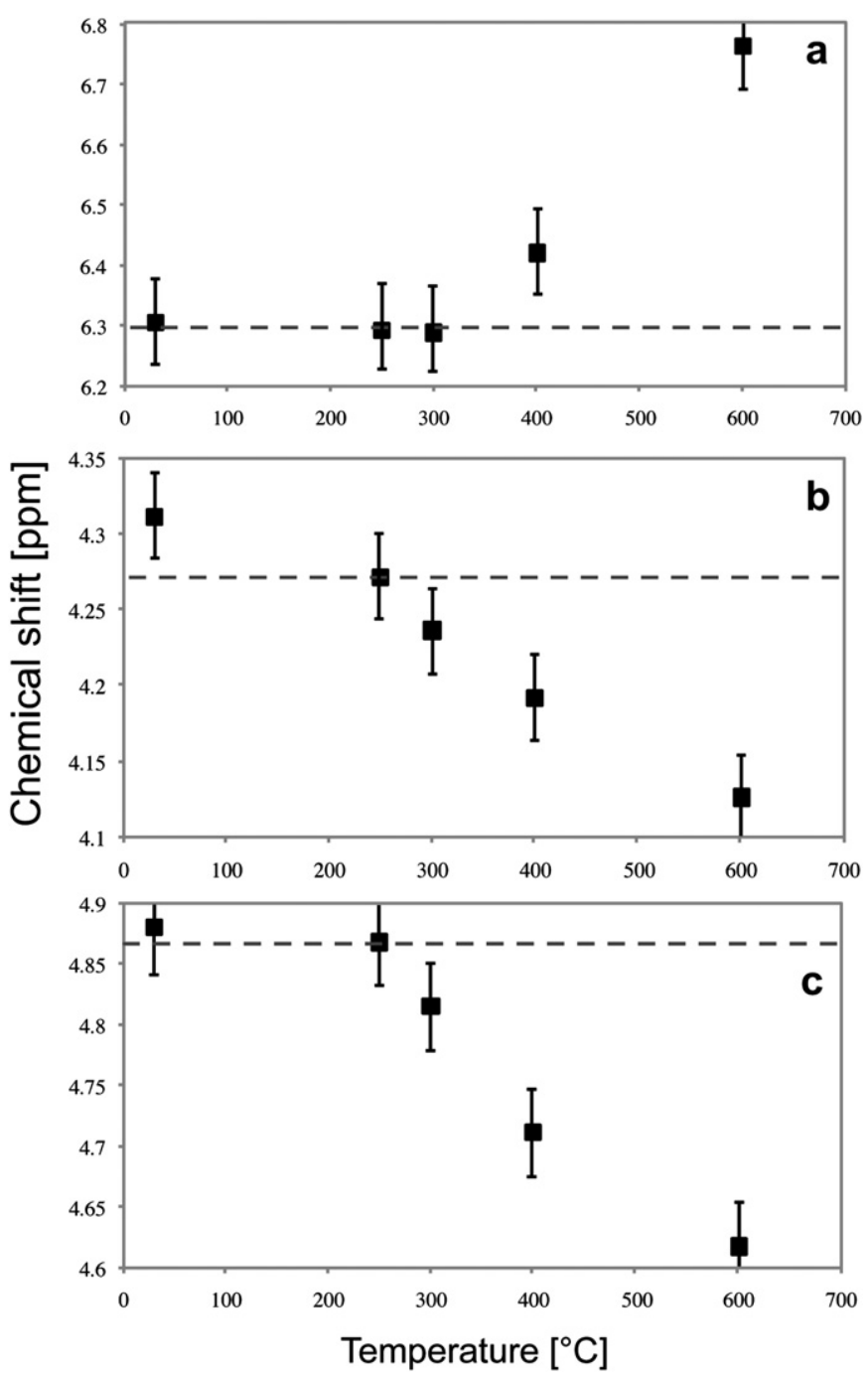

Fig. 6. ${ }^{1} \mathrm{H}$ chemical shifts of $\mathrm{SiOH}(\mathrm{a})$, the $\mathrm{H}_{2} \mathrm{O}$ multilayer (b) and free $\mathrm{H}_{2} \mathrm{O}$ (c) as a function of annealing temperature. Error bars were estimated based on the signal/ noise ratio of the NMR spectra. Further explanations in the text. 


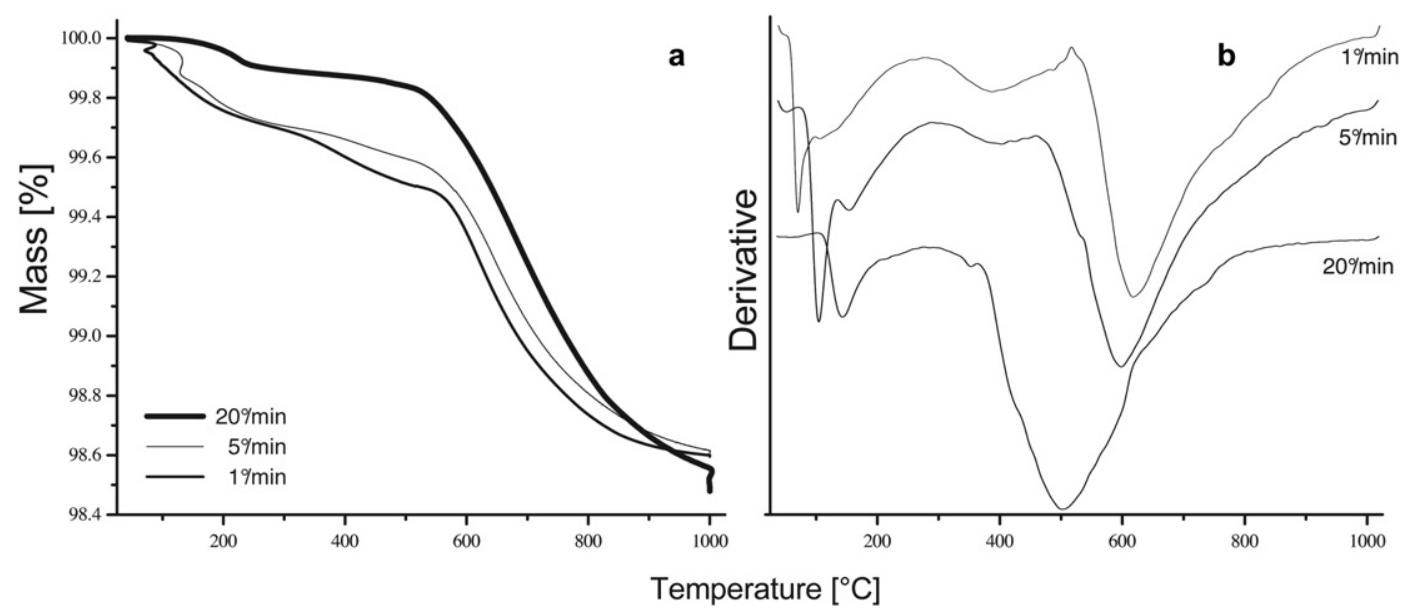

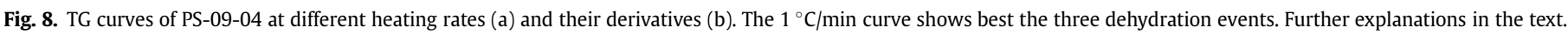

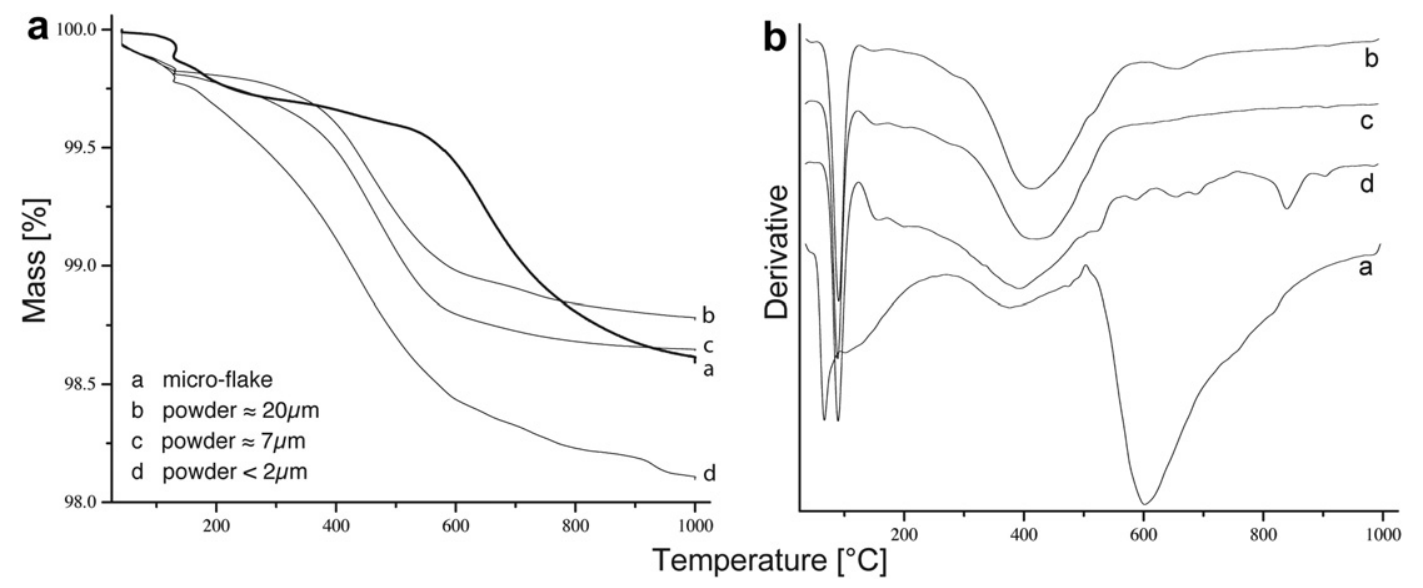

Fig. 9. The $1^{\circ} \mathrm{C} / \mathrm{min}$ TG curves of powders of PS-09-04 with different particle sizes (a) and their derivatives (b). Further explanations in the text.

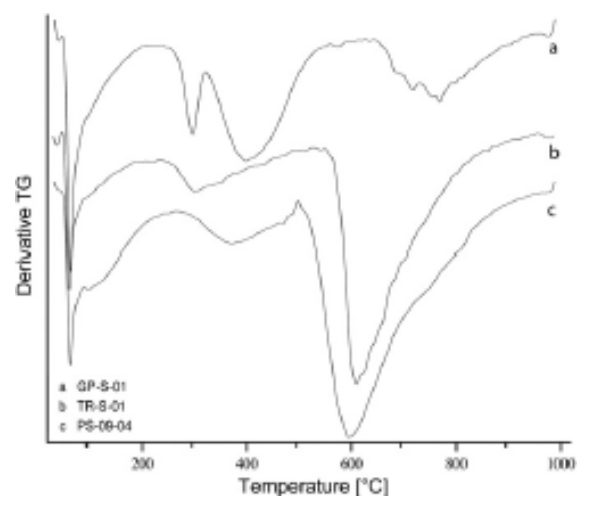

Fig. 10. Comparison between three derivatives of the $1{ }^{\circ} \mathrm{C} / \mathrm{min} \mathrm{TG}$ curves of GP-S-01, TR-S-01 and PS-09-04. Further explanations in the text. 


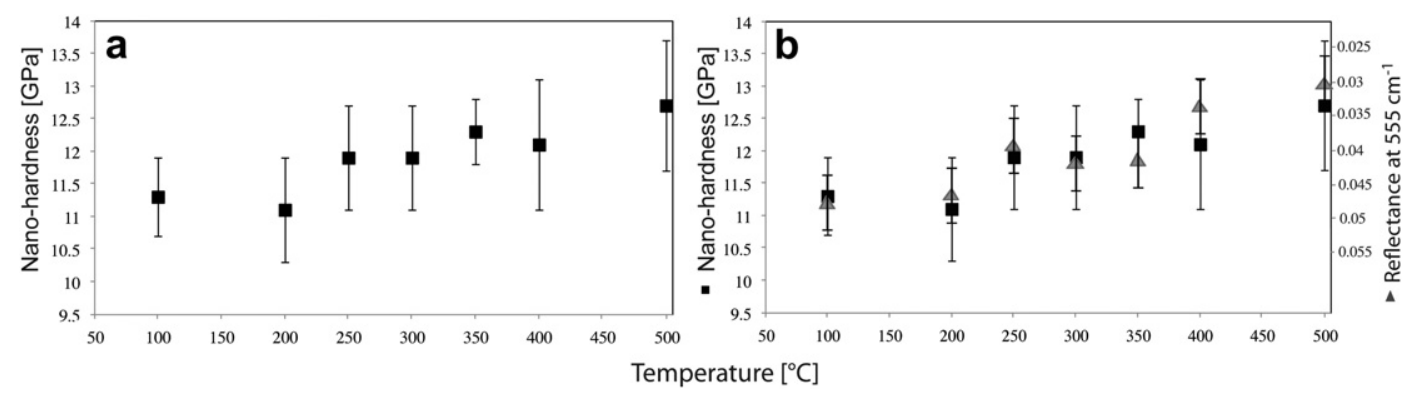

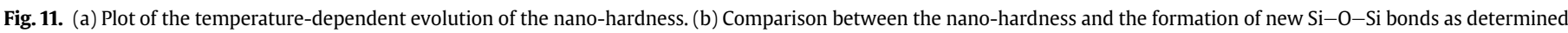

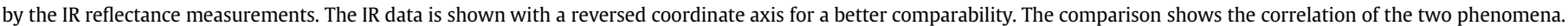

a

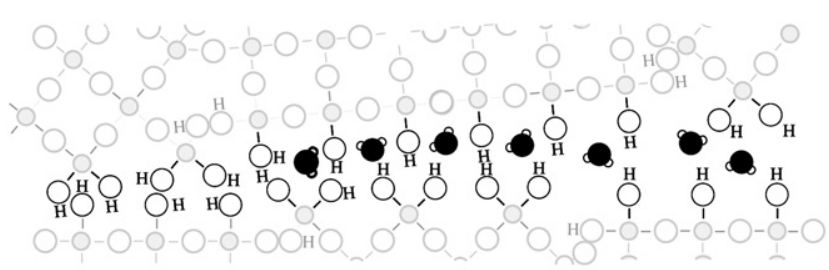

b

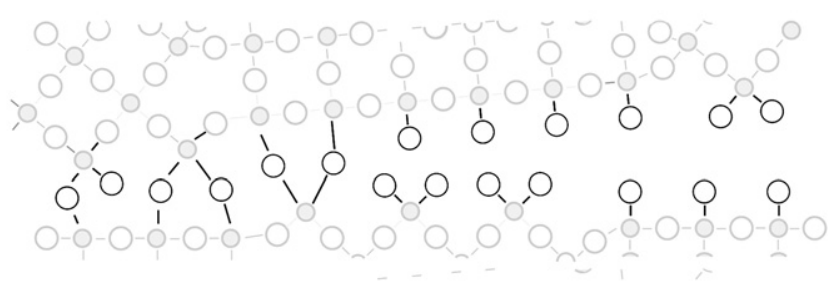

C

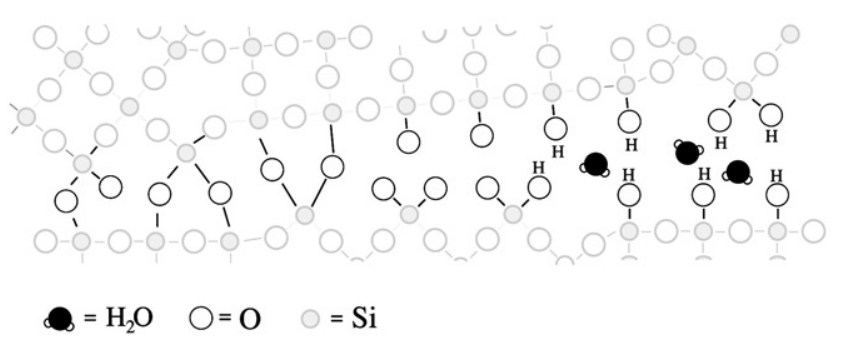

Fig. 12. Scheme of the reduction of open porosity of chalcedony upon heat treatment. (a) Before heating, (b) in the dehydrated state directly after annealing and (c) after rehydration. Upon heating, water molecules are evaporated and silanole is reduced to $\mathrm{SiO}^{-}$. New $\mathrm{Si}-\mathrm{O}-\mathrm{Si}$ bonds can be formed where the pore walls are close enough. In the zones where this reaction is not possible, $\mathrm{SiOH}$ is again built after rehydration of the quenched sample. The free charges of $\mathrm{SiO}^{-}$remain uncompensated where these ions are at sites that cannot be re-penetrated by water upon rehydration. 